\title{
Genetic characterisation of novel, highly pathogenic avian influenza (HPAI) H5N6 viruses isolated in birds, South Korea, November 2016
}

Y Si ${ }^{12}$, IW Lee ${ }^{12}$, E Kim ${ }^{1}$, Y Kim ${ }^{1}$, H Kwon ${ }^{1}$, S Park ${ }^{1}$, HD Nguyen ${ }^{1}$, SM Kim ${ }^{1}$, J Kwon ${ }^{1}$, W Choi ${ }^{1}$, YH Beak ${ }^{1}$, M Song ${ }^{1}$, C Kim ${ }^{3}$, RJ Webby ${ }^{4}$, Y Choi ${ }^{1}$

1. College of Medicine and Medical Research Institute, Chungbuk National University, Cheongju, Republic of Korea

2. These authors contributed equally to this work

3. College of Veterinary Medicine, Chungnam National University, Daejeon, Republic of Korea

4. Department of Infectious Diseases, St. Jude Children's Research Hospital, Memphis, Tennessee, United States

Correspondence: Young Ki Choi (choiki55@chungbuk.ac.kr)

Citation style for this article:

Si Y, Lee IW, Kim E, Kim Y, Kwon H, Park S, Nguyen HD, Kim SM, Kwon J, Choi W, Beak YH, Song M, Kim C, Webby RJ, Choi Y. Genetic characterisation of novel, highly pathogenic avian influenza (HPAI) H5N6 viruses isolated in birds, South Korea, November 2016. Euro Surveill. 2017;22(1):pii=30434. DOI: http://dx.doi. org/10.2807/1560-7917.ES.2017.22.1.30434

Article submitted on 08 December 2016 / accepted on 05 January 2017 / published on 05 January 2017

A novel genotype of $\mathrm{H}_{5} \mathrm{~N} 6$ influenza viruses was isolated from migratory birds in South Korea during November 2016. Domestic outbreaks of this virus were associated with die-offs of wild birds near reported poultry cases in Chungbuk province, central South Korea. Genetic analysis and animal studies demonstrated that the Korean $\mathrm{H}_{5} \mathrm{~N} 6$ viruses are highly pathogenic avian influenza (HPAl) viruses and that these viruses are novel reassortants of at least three different subtypes $\left(\mathrm{H}_{5} \mathrm{~N}_{6}, \mathrm{H}_{4} \mathrm{~N}_{2}\right.$ and $\left.\mathrm{H}_{1} \mathrm{~N}_{1}\right)$.

In late October 2016, isolation was reported of highly pathogenic avian influenza (HPAl) $\mathrm{H}_{5} \mathrm{~N} 6$ virus from wild migratory birds in South Korea for the first time [1] which subsequently has caused continuous outbreaks in domestic poultry. In Southeast Asia, HPAI $\mathrm{H}_{5}$ viruses have been continuously isolated from wild birds and domestic poultry since the first detection of $A / G s /$ Guangdong/1/1996 (Gs/GD/1996, $\mathrm{H}_{5} \mathrm{~N}_{1}$ ) in poultry in 1996 [2]. These viruses cause high mortality resulting in serious economic losses in the poultry industry and they spread widely. The HPAI $\mathrm{H}_{5} \mathrm{~N}_{1}$ subtype was stably maintained for more than a decade before it started to evolve into the novel reassortant $\mathrm{HPAl} \mathrm{H}_{5} \mathrm{Nx}$ virus in 2008 [3]. The HPAI $\mathrm{H}_{5} \mathrm{~N}_{5}$, which was the first $\mathrm{H}_{5} \mathrm{Nx}$ subtype isolated, is a member of clade 2.3.4 while most $\mathrm{H}_{5} \mathrm{Nx}$ recently circulating worldwide, including $\mathrm{H}_{5} \mathrm{~N}_{2}, \mathrm{H}_{5} \mathrm{~N} 6$ and $\mathrm{H}_{5} \mathrm{~N} 8$, cluster into a sublineage of clade 2.3.4 designated as 2.3.4.4 [4]. The clade 2.3.4.4 $\mathrm{H}_{5} \mathrm{~N} 8$ influenza virus was first reported in South Korea in 2014 and subsequently spread to East Asia, Europe, and further to North America and created novel $\mathrm{H}_{5} \mathrm{Nx}$ subtypes [5-7].

In addition to the $\mathrm{H}_{5} \mathrm{~N} 8$ viruses, the clade 2.3.4.4 $\mathrm{H}_{5} \mathrm{~N} 6$ virus that first emerged in China in 2013, spread to
Laos and Vietnam in 2014/15 with evidence of sustained transmission and further geographical spread within both countries. The $\mathrm{H}_{5} \mathrm{~N} 6$ virus caused fatalities in poultry and now appears to be endemic in mainland China, Laos, and Vietnam [8]. Although the $\mathrm{H}_{5} \mathrm{~N} 8$ virus is contained in clade 2.3.4.4 haemagglutinin (HA) gene pools along with HPAI H${ }_{5} \mathrm{~N} 6$ viruses, it is relatively low pathogenic in mammalian hosts $[5,9]$, and no human cases have been reported thus far. However, the avian influenza virus subtype $\mathrm{H}_{5} \mathrm{~N} 6$ caused 16 human infections including six fatalities in China as of November 2016 [10].

During late October 2016, the clade 2.3.4.4 H5 N6 influenza virus was first detected in faecal specimens of migratory wild birds in South Korea and has subsequently caused poultry outbreaks in South Korea from mid-November 2016 [11]. The first reported poultry cases in Chungbuk province in central South Korea were associated with nearby die-offs of wild birds leading to speculation that migratory waterfowl were the source of infection. We report here the genetic characterisation of the $\mathrm{H}_{5} \mathrm{~N} 6$ viruses isolated from faecal specimens of migratory wild birds during these first outbreaks and the investigation of their pathogenic potential in chickens.

\section{Genetic characterisation of novel avian influenza $\mathrm{A}(\mathrm{H} 5 \mathrm{~N} 6)$ viruses}

Four $\mathrm{H}_{5} \mathrm{~N} 6$ viruses were isolated from faecal samples obtained from migratory bird habitats in Chungbuk Province during a surveillance study conducted on 18 November 2016. Full-length genomic sequence analysis revealed that the viruses showed $99.9 \%$ to $100 \%$ nucleotide (nt) homology to one another (data not shown). One representative virus, A/Environment/ 


\section{FIGURE 1}

Phylogenetic tree of H5 segment of novel H5N6 viruses, South Korea, November 2016

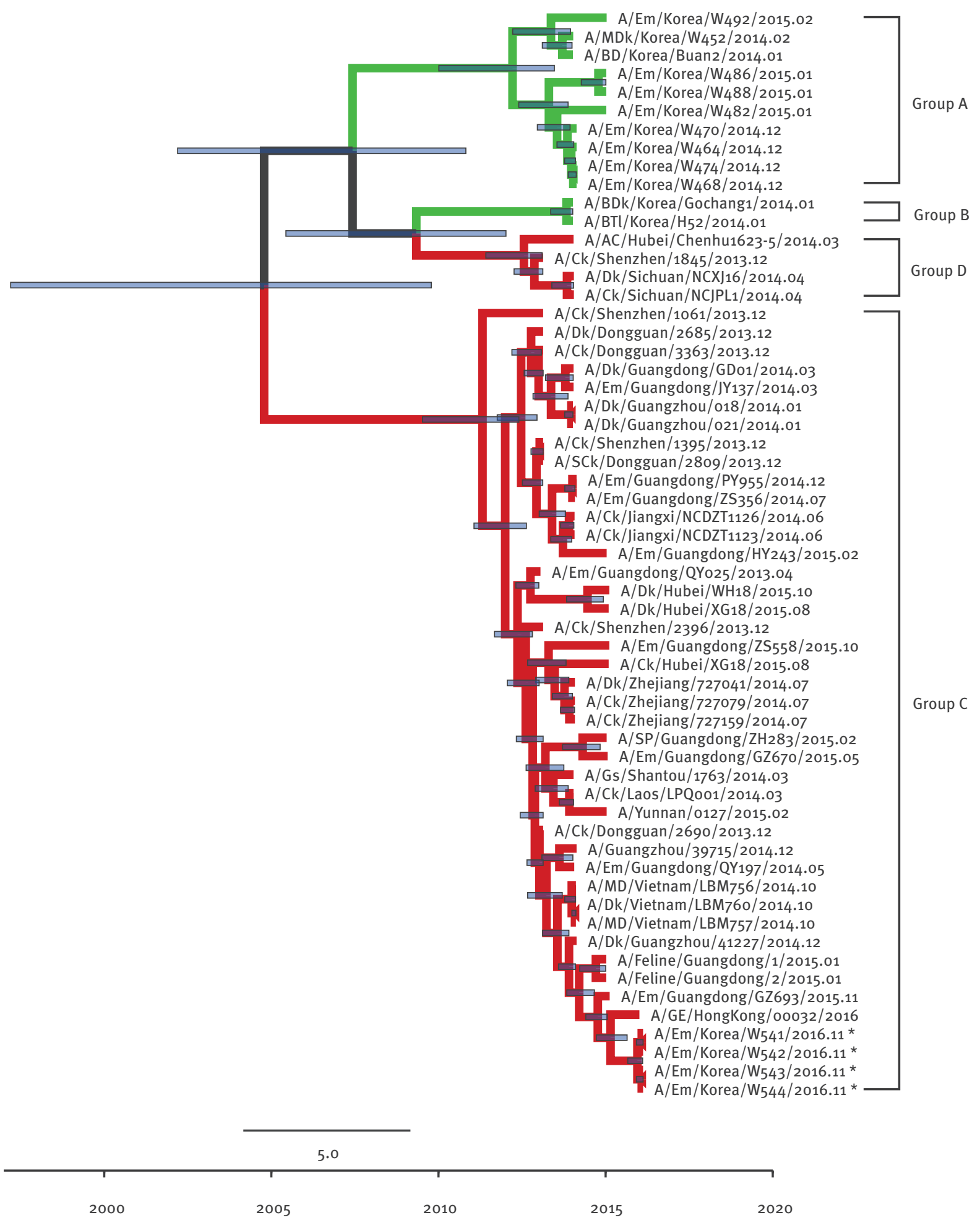

AC: anas crecca; BDk: breeder duck; BD: broiler duck; BTl: baikal teal; Ck: chicken; Dk: duck; Em: environment; GE, great egret; Gs, goose; HA: haemagglutinin; MD, mallard; nt: nucleotide; SCk: silkie chicken; SP: syrrhaptes paradoxus.

To investigate the origins of novel $\mathrm{H}_{5} \mathrm{~N} 6$ viruses (A/Em/Korea/W541/2016, A/Em/Korea/W542/2016, A/Em/Korea/W543/2016, and A/Em/ Korea/W544/2016: marked with asterisks), full-length nt sequences of each segment were compared with available $\mathrm{H}_{5} \mathrm{Nx}$ and high blast scoring virus sequences from the GenBank. The deposited GenBank accession numbers of HA genes are KY272997-KY273000. Time-scaled phylogenies (dates shown on the horizontal axis) were inferred using strict-clock Bayesian Markov chain Monte Carlo analysis. Times of most recent common ancestors with $95 \%$ highest posterior density intervals are shown by the horizontal bars at each node (violet line). The month of isolation is indicated at the end of the viral nomenclature. The green line indicates the $\mathrm{H}_{5} \mathrm{~N} 8$ subtype while the red line indicates the $\mathrm{H}_{5} \mathrm{~N} 6$ subtype. 


\section{FIGURE 2}

Phylogenetic tree of N6 segment of novel H5N6 viruses, South Korea, November 2016

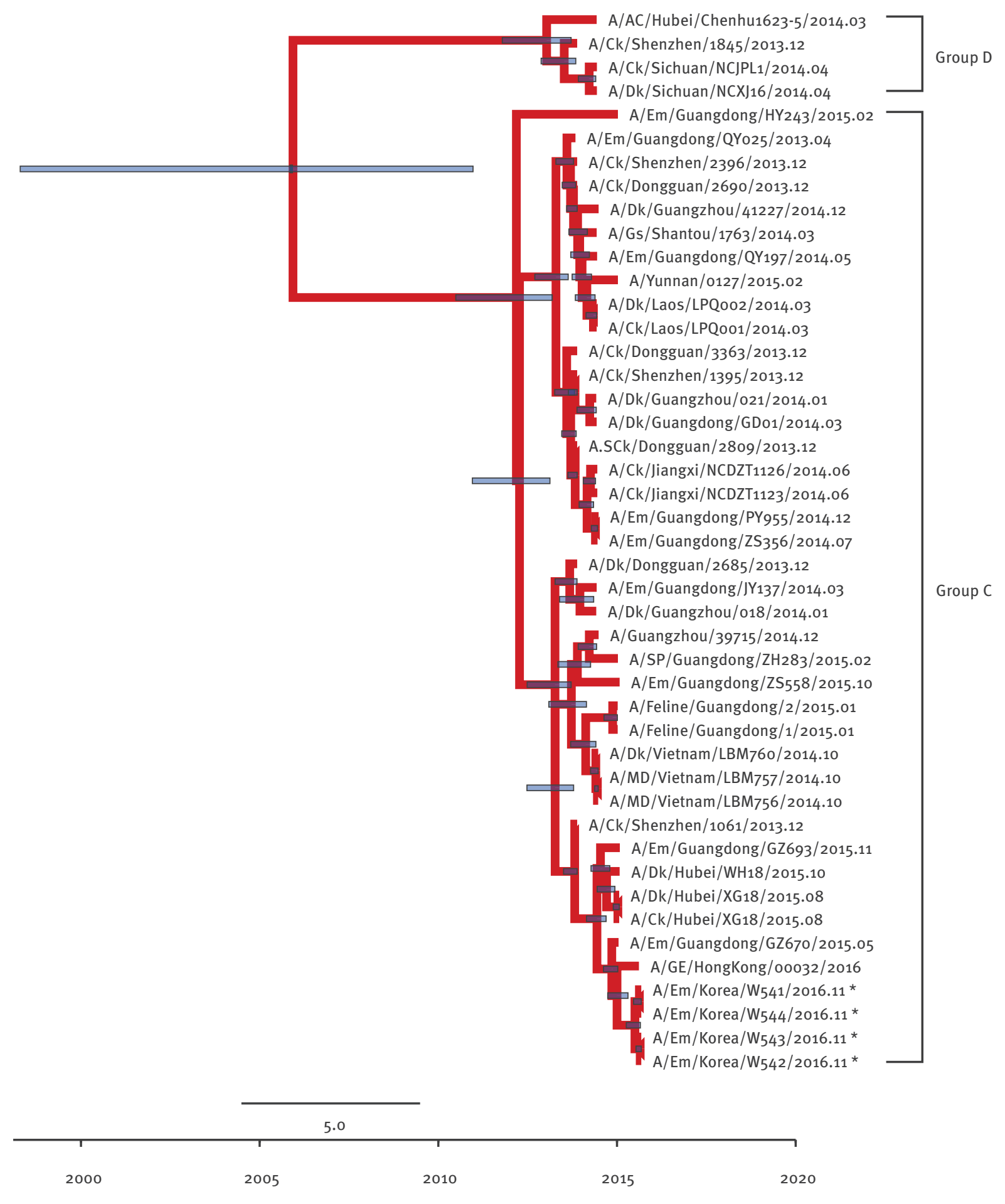

AC: anas crecca; BDk: breeder duck; BD: broiler duck; BTl: baikal teal; Ck: chicken; Dk: duck; Em: environment; GE, great egret; Gs, goose; MD, mallard; NA: neuraminidase; nt: nucleotides; SCk: silkie chicken; SP: syrrhaptes paradoxus.

To investigate the origins of novel $\mathrm{H}_{5} \mathrm{~N} 6$ viruses (A/Em/Korea/W541/2016, A/Em/Korea/W542/2016, A/Em/Korea/W543/2016, and A/Em/ Korea/W544/2016: marked with asterisks), full-length nt sequences of each segment were compared with available $\mathrm{H}_{5} \mathrm{Nx}$ and high blast scoring virus sequences from the GenBank. The deposited GenBank accession numbers of NA genes are KY273005-KY273008. Time-scaled phylogenies (dates shown on the horizontal axis) were inferred using strict-clock Bayesian Markov chain Monte Carlo analysis. Times of most recent common ancestors with $95 \%$ highest posterior density intervals are shown by the horizontal bars at each node (violet line). The month of isolation is indicated at the end of the viral nomenclature. The green line indicates the $\mathrm{H}_{5} \mathrm{~N} 8$ subtype while the red line indicates the $\mathrm{H}_{5} \mathrm{~N} 6$ subtype. 


\section{FIGURE 3}

Phylogenetic tree of PB2 segment of novel H5N6 viruses, South Korea, November 2016

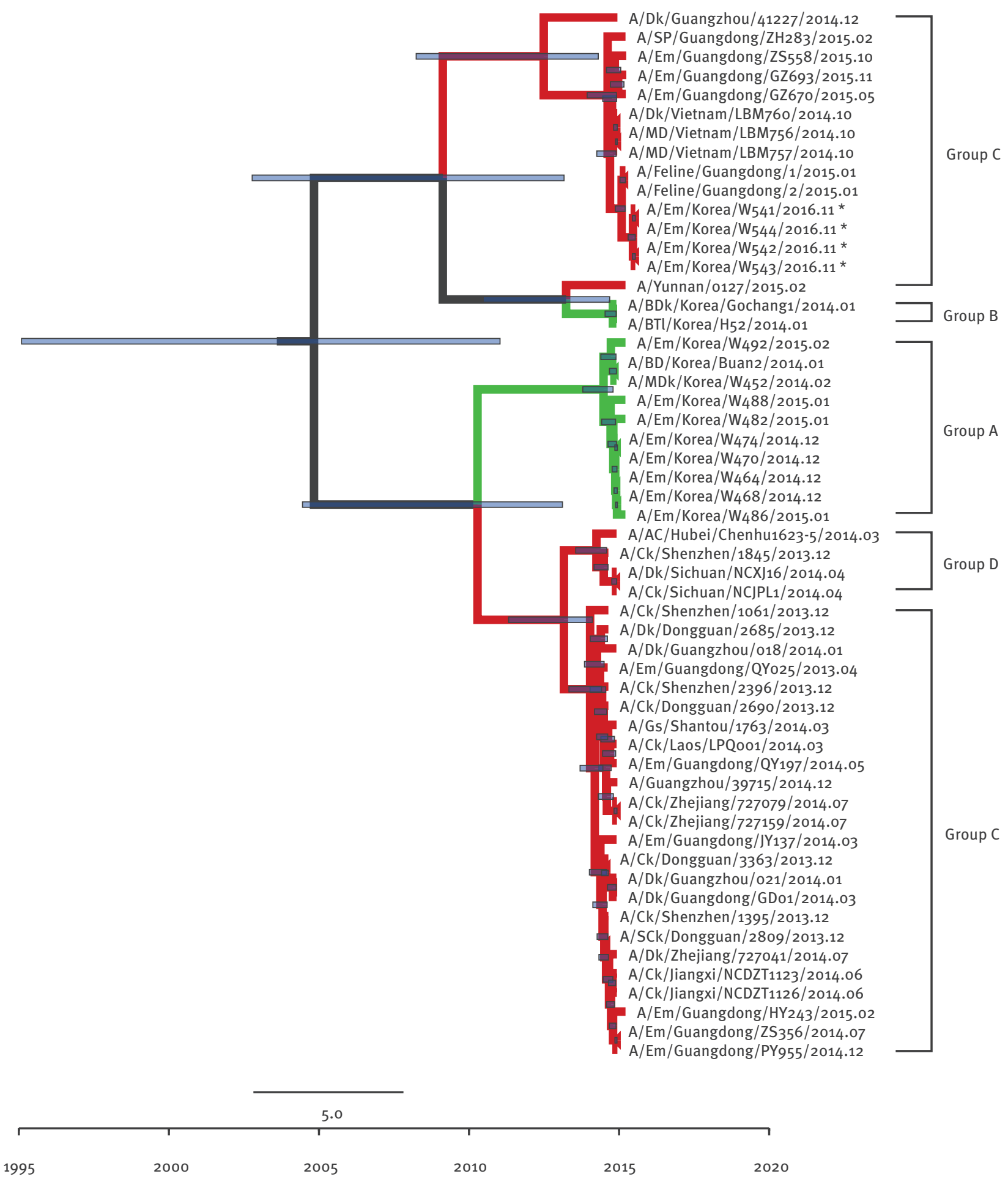

AC: anas crecca; BDk: breeder duck; BD: broiler duck; BTl: baikal teal; Ck: chicken; Dk: duck; Em: environment; GE, great egret; Gs, goose; MD, mallard; nt: nucleotide; PB: polymerase basic protein; SCk: silkie chicken; SP: syrrhaptes paradoxus.

To investigate the origins of novel $\mathrm{H}_{5} \mathrm{N6}$ viruses (A/Em/Korea/W541/2016, A/Em/Korea/W542/2016, A/Em/Korea/W543/2016, and A/Em/ Korea/W544/2016: marked with asterisks), full-length nt sequences of each segment were compared with available $\mathrm{H}_{5} \mathrm{Nx}$ and high blast scoring virus sequences from the GenBank. The deposited GenBank accession numbers of PB2 genes are KY273025-KY273028. Time-scaled phylogenies (dates shown on the horizontal axis) were inferred using strict-clock Bayesian Markov chain Monte Carlo analysis. Times of most recent common ancestors with $95 \%$ highest posterior density intervals are shown by the horizontal bars at each node (violet line). The month of isolation is indicated at the end of the viral nomenclature. The green line indicates the $\mathrm{H}_{5} \mathrm{~N} 8$ subtype while the red line indicates the $\mathrm{H}_{5} \mathrm{~N} 6$ subtype. 


\section{FIGURE 4}

Phylogenetic tree of NP segment of novel H5N6 viruses, South Korea, November 2016

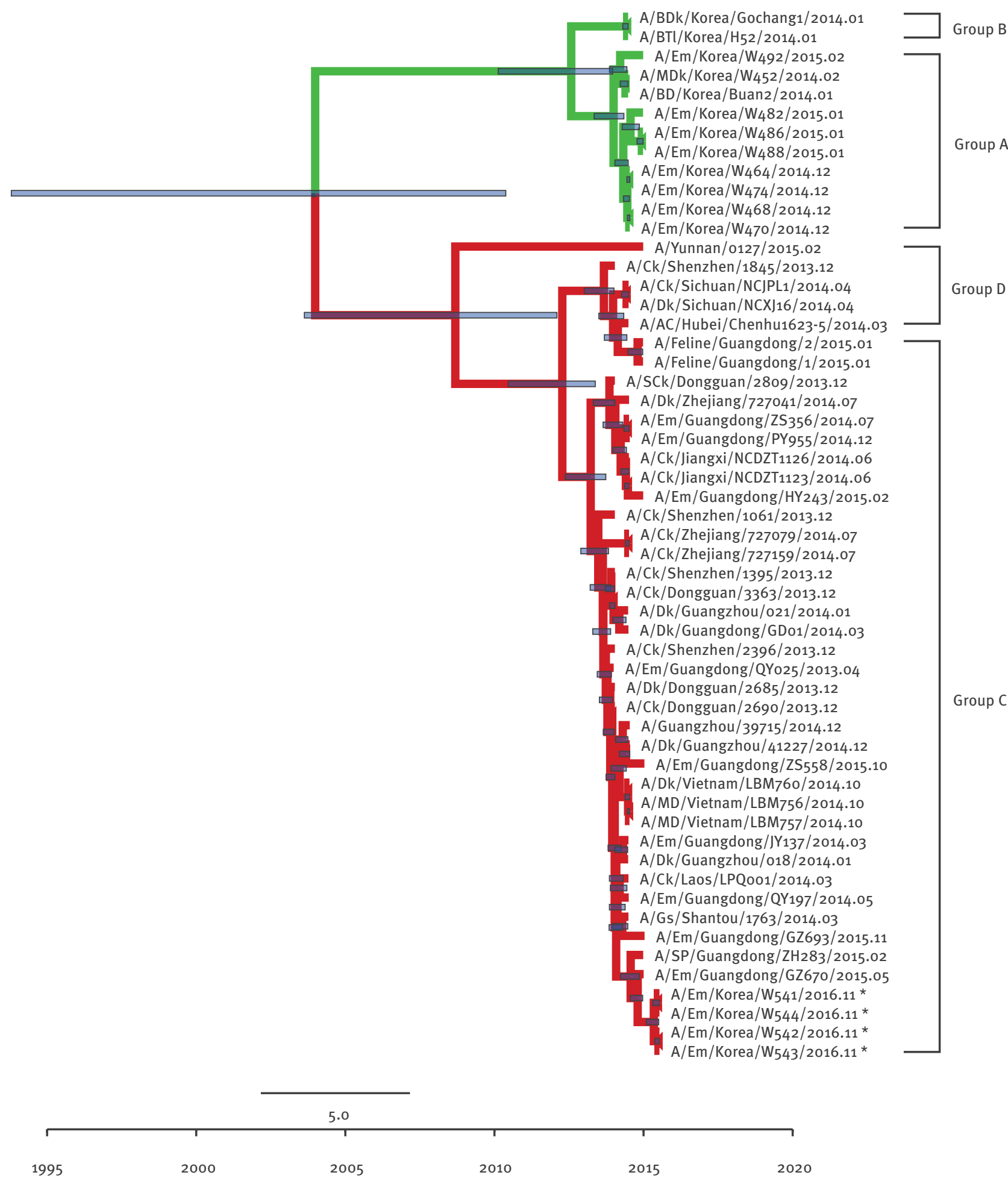

AC: anas crecca; BDk: breeder duck; BD: broiler duck; BTI: baikal teal; Ck: chicken; Dk: duck; Em: environment; GE, great egret; Gs, goose; MD, mallard; NP: nucleoprotein; nt: nucleotide; SCk: silkie chicken; SP: syrrhaptes paradoxus.

To investigate the origins of novel $\mathrm{H}_{5} \mathrm{N6}$ viruses (A/Em/Korea/W541/2016, A/Em/Korea/W542/2016, A/Em/Korea/W543/2016, and A/Em/ Korea/W544/2016: marked with asterisks), full-length nt sequences of each segment were compared with available $\mathrm{H}_{5} \mathrm{Nx}$ and high blast scoring virus sequences from the GenBank. The deposited GenBank accession numbers of NP genes are KY273009-KY273012. Time-scaled phylogenies (dates shown on the horizontal axis) were inferred using strict-clock Bayesian Markov chain Monte Carlo analysis. Times of most recent common ancestors with $95 \%$ highest posterior density intervals are shown by the horizontal bars at each node (violet line). The month of isolation is indicated at the end of the viral nomenclature. The green line indicates the $\mathrm{H}_{5} \mathrm{~N} 8$ subtype while the red line indicates the $\mathrm{H}_{5} \mathrm{~N} 6$ subtype. 


\section{FIGURE 5}

Phylogenetic tree of M segment of novel H5N6 viruses, South Korea, November 2016

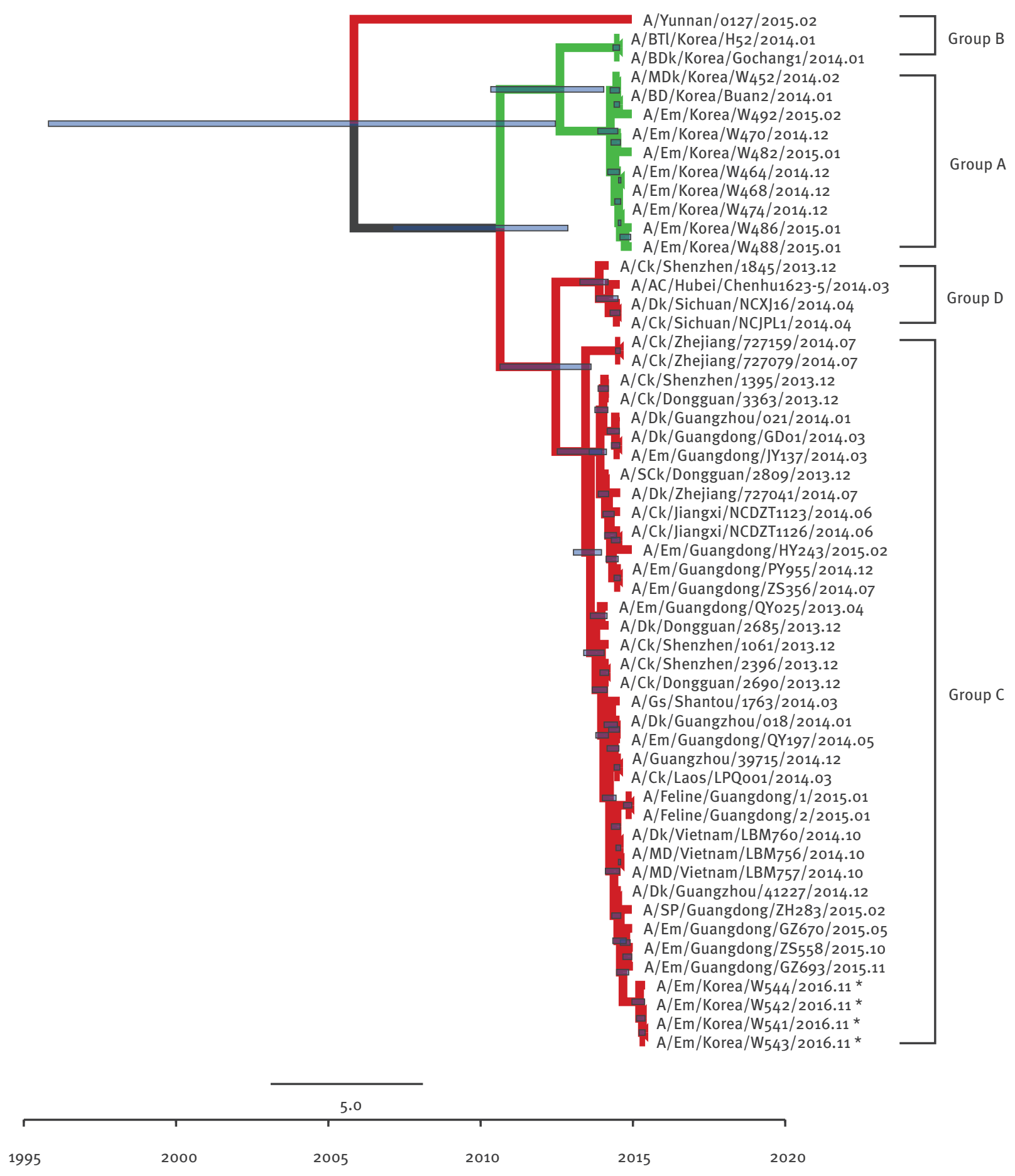

AC: anas crecca; BDk: breeder duck; BD: broiler duck; BTI: baikal teal; Ck: chicken; Dk: duck; Em: environment; GE, great egret; Gs, goose; M: matrix; MD, mallard; nt: nucleotide; SCk: silkie chicken; SP: syrrhaptes paradoxus.

To investigate the origins of novel $\mathrm{H}_{5} \mathrm{~N} 6$ viruses (A/Em/Korea/W541/2016, A/Em/Korea/W542/2016, A/Em/Korea/W543/2016, and A/Em/ Korea/W544/2016: marked with asterisks), full-length nt sequences of each segment were compared with available $\mathrm{H}_{5} \mathrm{Nx}$ and high blast scoring virus sequences from the GenBank. The deposited GenBank accession numbers of M genes are KY273001-KY273004. Time-scaled phylogenies (dates shown on the horizontal axis) were inferred using strict-clock Bayesian Markov chain Monte Carlo analysis. Times of most recent common ancestors with $95 \%$ highest posterior density intervals are shown by the horizontal bars at each node (violet line). The month of isolation is indicated at the end of the viral nomenclature. The green line indicates the $\mathrm{H}_{5} \mathrm{~N} 8$ subtype while the red line indicates the $\mathrm{H}_{5} \mathrm{~N} 6$ subtype. 


\section{FIGURE 6}

Phylogenetic tree of NS segment of novel H5N6 viruses, South Korea, November 2016

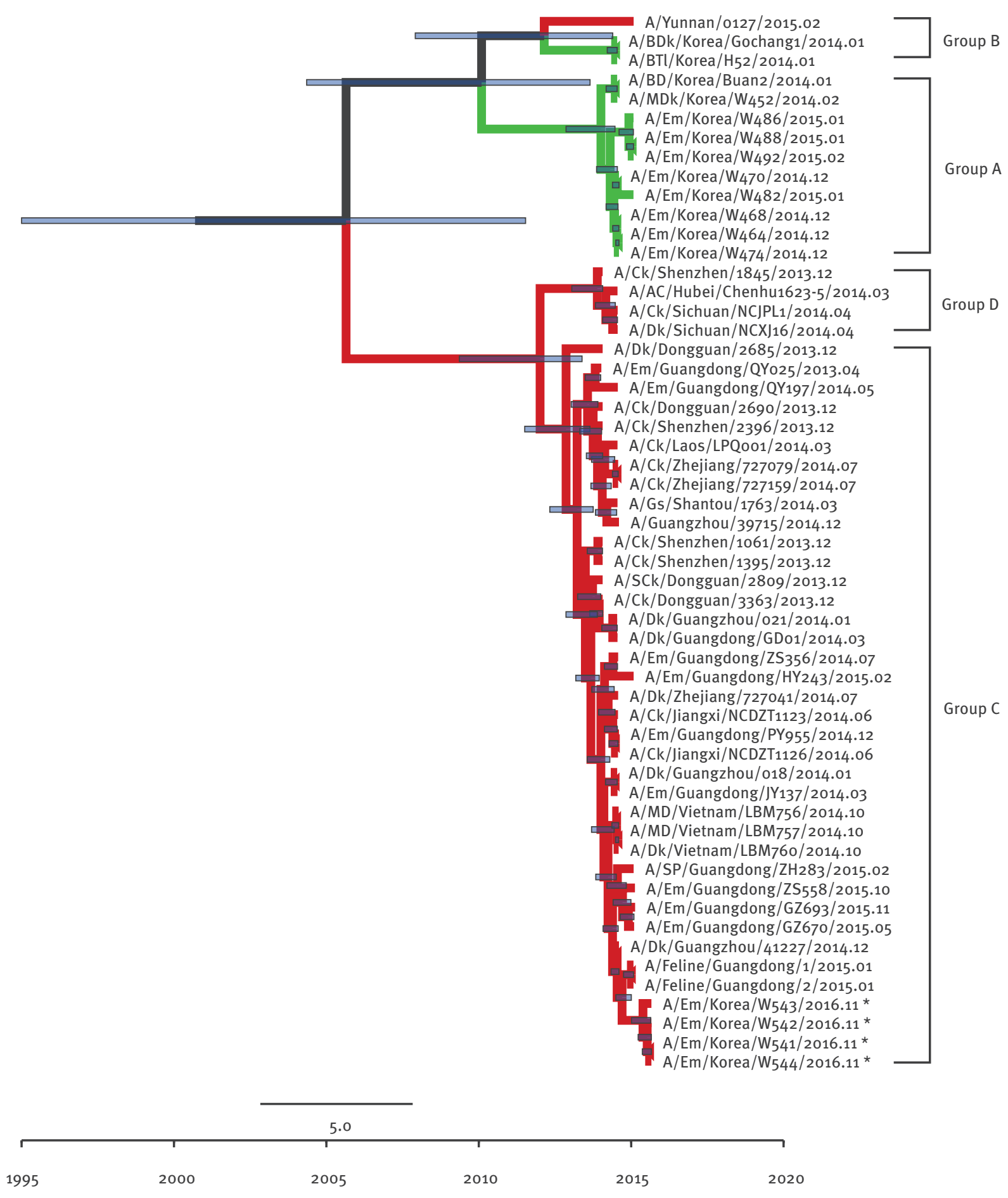

AC: anas crecca; BDk: breeder duck; BD: broiler duck; BTl: baikal teal; Ck: chicken; Dk: duck; Em: environment; GE, great egret; Gs, goose; MD, mallard; NS: nonstructural protein; nt: nucleotide; SCk: silkie chicken; SP: syrrhaptes paradoxus.

To investigate the origins of novel $\mathrm{H}_{5} \mathrm{~N} 6$ viruses (A/Em/Korea/W541/2016, A/Em/Korea/W542/2016, A/Em/Korea/W543/2016, and A/Em/ Korea/W544/2016: marked with asterisks), full-length nt sequences of each segment were compared with available $\mathrm{H}_{5} \mathrm{Nx}$ and high blast scoring virus sequences from the GenBank. The deposited GenBank accession numbers of NS genes are KY273013-KY273016. Time-scaled phylogenies (dates shown on the horizontal axis) were inferred using strict-clock Bayesian Markov chain Monte Carlo analysis. Times of most recent common ancestors with $95 \%$ highest posterior density intervals are shown by the horizontal bars at each node (violet line). The month of isolation is indicated at the end of the viral nomenclature. The green line indicates the $\mathrm{H}_{5} \mathrm{~N}_{8}$ subtype while the red line indicates the $\mathrm{H}_{5} \mathrm{~N} 6$ subtype. 


\section{FIGURE 7}

Phylogenetic tree of PB1 segment of novel H5N6 viruses, South Korea November 2016

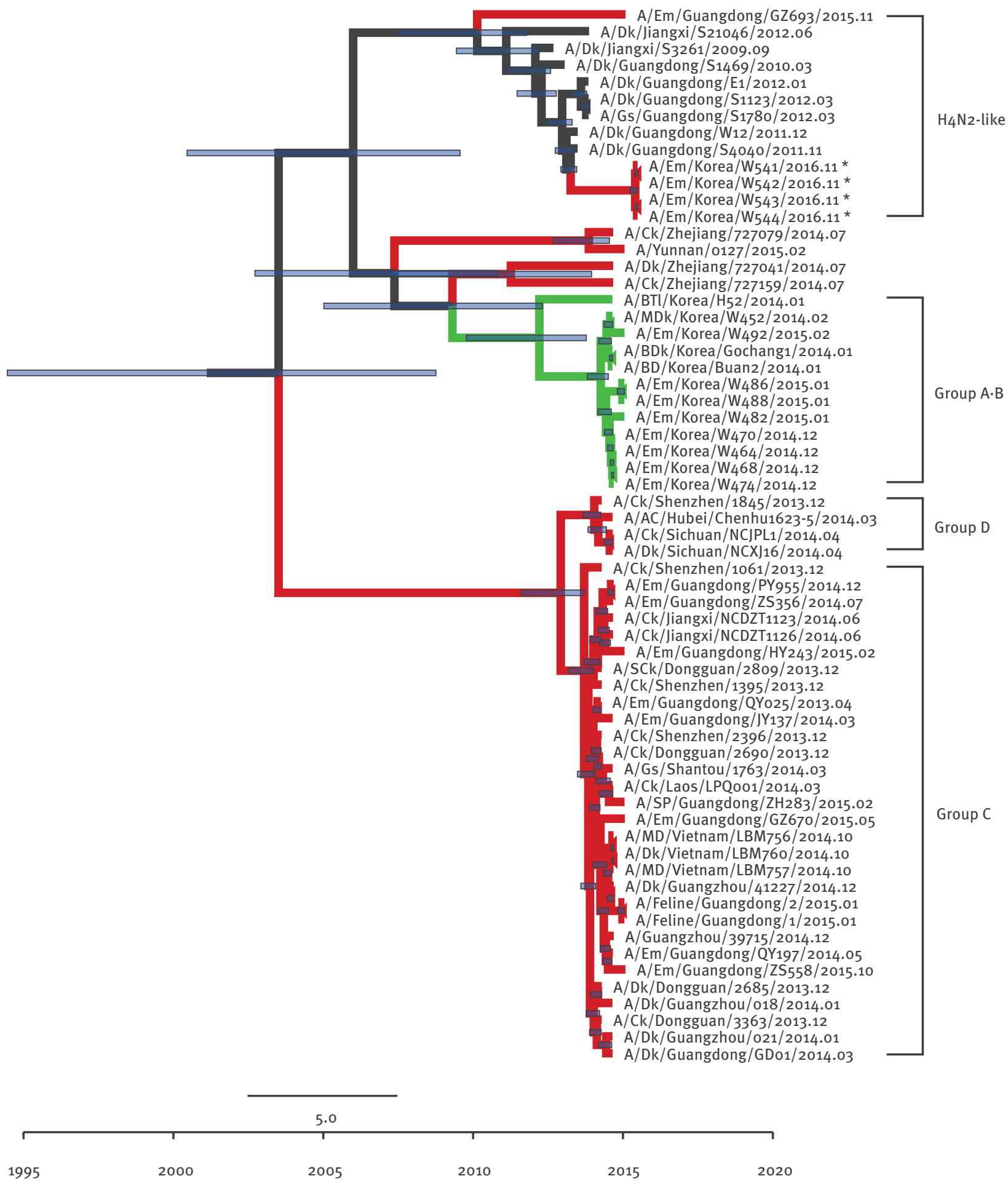

AC: anas crecca; BDk: breeder duck; BD: broiler duck; BTl: baikal teal; Ck: chicken; Dk: duck; Em: environment; GE, great egret; Gs, goose; MD, mallard; nt: nucleotide; PB: polymerase basic protein; SCk: silkie chicken; SP: syrrhaptes paradoxus.

To investigate the origins of novel H5N6 viruses (A/Em/Korea/W541/2016, A/Em/Korea/W542/2016, A/Em/Korea/W543/2016, and A/Em/ Korea/W544/2016: marked with asterisks), full-length nt sequences of each segment were compared with available $\mathrm{H}_{5} \mathrm{Nx}$ and high blast scoring virus sequences from the GenBank. The deposited GenBank accession numbers of PB1 genes are KY273021-KY273024. Time-Scaled phylogenies (dates shown on the horizontal axis) were inferred using strict-clock Bayesian Markov chain Monte Carlo analysis. Times of most recent common ancestors with $95 \%$ highest posterior density intervals are shown by the horizontal bars at each node (violet line). The month of isolation is indicated at the end of the viral nomenclature. The green line indicates the $\mathrm{H}_{5} \mathrm{~N} 8$ subtype while the red line indicates the $\mathrm{H}_{5} \mathrm{~N} 6$ subtype. 


\section{FIGURE 8}

Phylogenetic tree of PA segment of novel H5N6 viruses, South Korea, November 2016

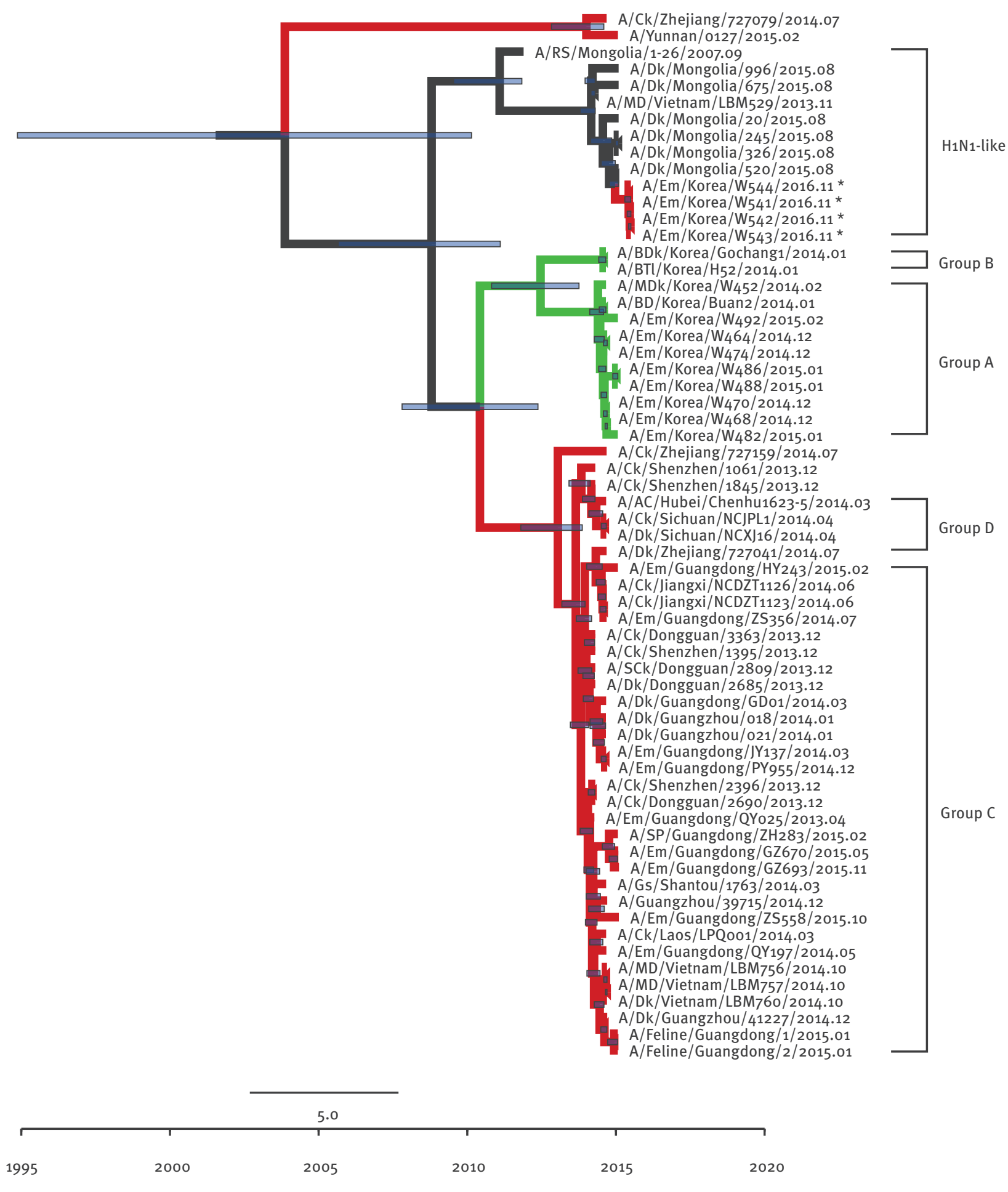

AC: anas crecca; BDk: breeder duck; BD: broiler duck; BTI: baikal teal; Ck: chicken; Dk: duck; Em: environment; GE, great egret; Gs, goose; M: matrix; MD, mallard; nt: nucleotide; PA: polymerase acidic; SCk: silkie chicken; SP: syrrhaptes paradoxus.

To investigate the origins of novel $\mathrm{H}_{5} \mathrm{~N} 6$ viruses (A/Em/Korea/W541/2016, A/Em/Korea/W542/2016, A/Em/Korea/W543/2016, and A/Em/ Korea/W544/2016: marked with asterisks), full-length nt sequences of each segment were compared with available $\mathrm{H}_{5} \mathrm{Nx}$ and high blast scoring virus sequences from the GenBank. The deposited GenBank accession numbers of PA genes are KY273017-KY273020. Time-scaled phylogenies (dates shown on the horizontal axis) were inferred using strict-clock Bayesian Markov chain Monte Carlo analysis. Times of most recent common ancestors with $95 \%$ highest posterior density intervals are shown by the horizontal bars at each node (violet line). The month of isolation is indicated at the end of the viral nomenclature. The green line indicates the $\mathrm{H}_{5} \mathrm{~N} 8$ subtype while the red line indicates the $\mathrm{H}_{5} \mathrm{~N} 6$ subtype. 


\section{FIGURE 9}

Illustration of genotypes and reassortment events resulting in the novel avain influenza H5N6 virus isolated in South Korea, November 2016

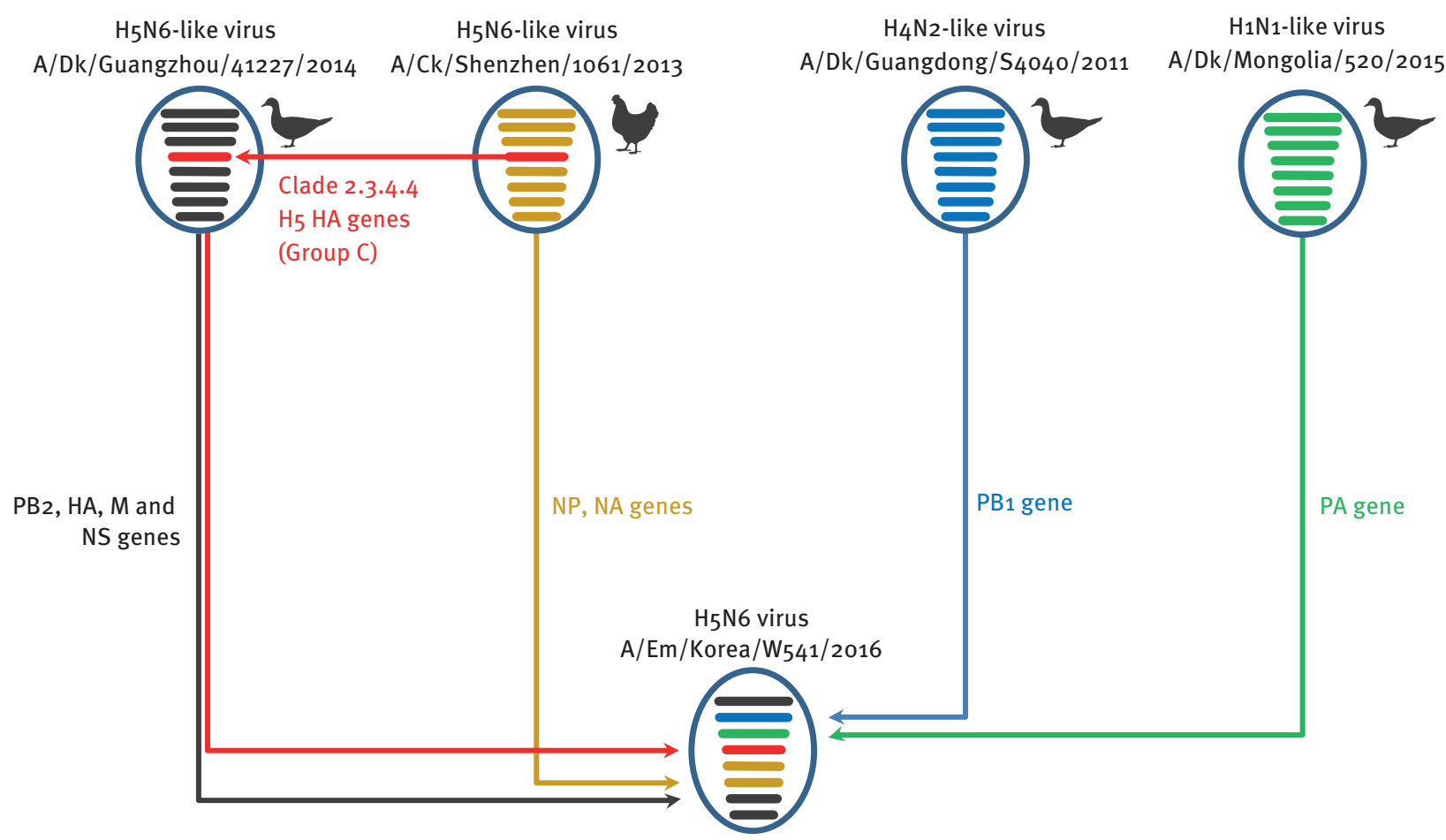

Ck: chicken; Dk: duck; Em: environment; HA: haemagglutinin; HPAI: highly pathogenic avian influenza; M: matrix; NA: neuraminidase; NS: nonstructural; NP: nucleoprotein; PA: polymerase acidic; PB: polymerase basic.

The eight gene segments in each illustrative virus particle represent PB2, PB1, PA, HA, NP, NA, M, and NS genes (in order from top to bottom). The $\mathrm{EM} / \mathrm{W}_{541}\left(\mathrm{H}_{5} \mathrm{~N}_{6}\right)$ virus was the reassortant with at least three different subtypes ( $\mathrm{H}_{5} \mathrm{~N}_{6}, \mathrm{H}_{4} \mathrm{~N}_{2}$, and $\left.\mathrm{H}_{1} \mathrm{~N}_{1}\right)$ from the natural gene pool in Eurasia. Each colour represents a virus lineage (Black indicates origin from A/Dk/Guangzhou/41227/2014-like; Orange, A/Ck/ Shenzhen/1061/13-like; Blue, A/Dk/Guangdong/S4040/11; Light Green, A/Dk/Mongolia/520/2015; Red, Clade 2.3.4.4 H5 HA genes).

Korea/W541/2016(H5N6), referred to as EM/W541 from here on, was selected for further study. Mitochondrial DNA sequence analysis of the faecal specimens revealed that Anas Platyrhynchos were the viral host [1]. Moreover, these $2016 \mathrm{H}_{5} \mathrm{~N} 6$ virus isolates belong to the A/Yunnan/0127/2015-like virus lineage (clade 2.3.4.4) detected in fatal human cases between 2014 and $2016[12,13]$. Molecular analysis demonstrated that the HA cleavage site of EM/W541 bears polybasic residues (RERRRKR/G) denoting a high-pathogenicity phenotype in chickens.

All four HPAI $\mathrm{H}_{5} \mathrm{~N} 6$ virus isolates maintained the glutamine residue at position 226 ( $\mathrm{H}_{3}$ numbering) and a glycine residue at position 228 , which is suggestive of preferential binding to sialic acid receptors joined to sugar chains through an a-2,3 linkage, as is typical for avian influenza viruses. However, a characteristic of all $\mathrm{H}_{5} \mathrm{~N} 6$ virus isolates was one amino acid deletion (133 site of $\mathrm{HA}_{1}$ ) relative to the other clade 2.3.4.4 HA genes (ex, MDk/Korea/W452/14), which is commonly found in avian influenza $\mathrm{H}_{5} \mathrm{~N} 6$ viruses (Table).
The deletion at this position alters the $3 \mathrm{D}$ structure of the receptor binding unit causing an alteration of the $\mathrm{HA}$ receptor binding specificity and resulting in an increased affinity for the a-2,6 linkage $[14,15]$. A similar deletion has occurred and is maintained in 2.2.1.2 viruses in Egypt [14]. These viruses bear considerable zoonotic potential. In addition, the Korean $\mathrm{H}_{5} \mathrm{~N} 6$ isolates had the characteristic 20 amino acid NA stalk deletion (49 to 68 sites) compared with the A/Ck/ Sichuan/NCJPL1/2014 virus, whereas a substitution associated with resistance to NA inhibitors was not noted. The isolates also possess functional polymerase basic (PB)1-F2 proteins, which have been shown to impact on host defence mechanisms and enhance pathogenicity in vivo. However, no other mammalianadaptive molecular determinants were observed in the viral genome [16]. The 2016 Korean virus isolates bear aspartic acid in place of glutamic acid at position 92 of the non-structural (NS)1 protein, which is responsible for attenuating anti-viral host interferon responses [17] and the C-terminal PDZ-binding motifs are both ESEV, which is typical for avian viruses and confers severe disease phenotype in mice [18]. 
Molecular analysis of influenza A subtype H5 viruses emerging in November 2016 compared with previously isolated H5 viruses*

\begin{tabular}{|c|c|c|c|c|c|c|c|c|c|c|c|c|c|c|c|c|c|c|}
\hline \multirow{3}{*}{ Viruses $^{a}$} & \multirow{3}{*}{$\begin{array}{c}\text { HA clade } \\
\text { classification }\end{array}$} & \multicolumn{9}{|c|}{ HA sequence (aa) } & \multirow{3}{*}{$\begin{array}{c}\begin{array}{c}\text { HA } \\
\text { deletion }\end{array} \\
133 \\
\end{array}$} & \multirow{3}{*}{$\begin{array}{c}\begin{array}{c}\text { NA stalk } \\
\text { deletion }\end{array} \\
49-68 \\
\end{array}$} & \multicolumn{3}{|c|}{ NS1 } & \multirow{2}{*}{\multicolumn{2}{|c|}{$\begin{array}{c}\mathrm{PB}_{2} \\
\text { sequence } \\
\text { at aa }\end{array}$}} & \multirow{3}{*}{$\begin{array}{c}\text { Expression } \\
\text { of } \mathrm{PB} 1-\mathrm{F} 2 \\
\text { protein }\end{array}$} \\
\hline & & $\begin{array}{l}\text { Cleavage } \\
\text { site }\end{array}$ & \multicolumn{8}{|c|}{ Receptor binding sites } & & & $\begin{array}{l}\text { Deletion } \\
\text { of aa }\end{array}$ & & sidue at & & & \\
\hline & & $335-348^{b}$ & 158 & 193 & 222 & 224 & 226 & 227 & 228 & 318 & & & & 92 & C-term & 627 & 701 & \\
\hline $\begin{array}{l}\text { EM/Korea/ } \\
\text { W541/16 } \\
\end{array}$ & $2.3 \cdot 4 \cdot 4$ & RERRR_KR/G & $\mathrm{N}$ & $\mathrm{N}$ & Q & $\mathrm{N}$ & Q & Q & G & $\mathrm{T}$ & YES & YES & YES & E & ESEV & E & D & YES \\
\hline $\begin{array}{l}\text { Yunnan/ } \\
\text { China/o127/15 }\end{array}$ & $2.3 \cdot 4 \cdot 4$ & RERRR_KR/G & N & $\mathrm{N}$ & Q & $\mathrm{N}$ & Q & $\mathrm{R}$ & G & $\mathrm{T}$ & YES & YES & NO & D & KPEV & $\mathrm{K}$ & D & YES \\
\hline $\begin{array}{l}\text { Ck/Sichuan/ } \\
\text { NCJPL1/2014 }\end{array}$ & $2 \cdot 3 \cdot 4 \cdot 4$ & RERRR_KR/G & $\mathrm{N}$ & $\mathrm{N}$ & Q & $\mathrm{N}$ & Q & $\mathrm{R}$ & G & T & NO & NO & YES & $\mathrm{E}$ & ESEV & $\mathrm{E}$ & D & YES \\
\hline $\begin{array}{l}\text { MDk/Korea/ } \\
\text { W452/14 }\end{array}$ & $2 \cdot 3 \cdot 4 \cdot 4$ & RERRR_KR/G & N & $\mathrm{N}$ & Q & $\mathrm{N}$ & Q & $\mathrm{R}$ & G & T & NO & NO & NO & D & ESEV & $\mathrm{E}$ & D & YES \\
\hline $\begin{array}{l}\text { BDk/Korea/ } \\
\text { Gochang1/14 }\end{array}$ & $2.3 \cdot 4 \cdot 4$ & RERRR_KR/G & N & $\mathrm{N}$ & Q & $\mathrm{N}$ & Q & $\mathrm{R}$ & G & T & NO & NO & NO & D & ESEV & $\mathrm{E}$ & D & YES \\
\hline $\begin{array}{l}\text { Em/Korea/ } \\
\text { W149/06 }\end{array}$ & 2.2 & GERRRKKR/G & N & K & $\mathrm{K}$ & N & Q & $\mathrm{s}$ & G & T & NO & YES & YES & D & ESKV & $\mathrm{K}$ & D & YES \\
\hline $\begin{array}{l}\text { MDk/Korea/ } \\
\text { W401/11 }\end{array}$ & 2.3 .2 & RERRR_KR/G & D & $\mathrm{R}$ & $\mathrm{K}$ & N & Q & $\mathrm{s}$ & G & T & NO & YES & YES & D & ESEV & E & D & YES \\
\hline $\begin{array}{l}\text { Egypt/ } \\
\mathrm{MOH} / 7271 / 14^{\mathrm{c}}\end{array}$ & 2.2 .1 .2 & GERRRKKR/G & $\mathrm{N}$ & $\mathrm{R}$ & $\mathrm{k}$ & $\mathrm{N}$ & Q & $\mathrm{s}$ & G & T & YES & YES & YES & D & ESEV & $\mathrm{k}$ & D & YES \\
\hline
\end{tabular}

Aa: amino acid; BDk: Breeder duck; C-term: 4 amino acid sequence at the C-terminal end; Em: environment; HA: haemagglutinin; HPAI: highly pathogenic avian influenza; MDk: mallard duck; RBS: receptor binding site; $\mathrm{MOH}$ : Ministry of health; NA: neuraminidase; NS: nonstructural protein; PB: polymerase basic protein.

The accession numbers of each virus are followed: Yunnan/China/0127/15: KT245143 KT245150, Ck/Sichuan/NCJPL1/2014: PB2-KM251533, PB1- KM251523, PAKM251513, HA-KM251463, NP-KM251493, NA-KM251486, M-KM251473, and NS-KM251503, MDk/Korea/W452/14: KJ746108 KJ746115, BDk/Korea/Gochang1/14 : KJ413831 KJ413838, EM/Korea/W149/06 : EU233731 EU233738, MDk/Korea/W401/11 : JN202558 JN202572, Egypt/MOH/7271/14 : KP702162 KP702169, and EM/Korea/W541/16 : KY272997 KY273025

a The isolates in boldface are the 2016 Korean HPAI H5N6 virus examined in this study.

${ }^{b} \mathrm{H}_{3}$ numbering.

' Human isolates.

\section{Phylogenetic analyses}

To clarify the origins of $E M / W_{541}$, phylogenetic analyses were conducted with available $\mathrm{H}_{5} \mathrm{Nx}$ virus sequences and other $\mathrm{N} 6$ viruses from the National Center for Biotechnology Information (NBCl) GenBank database. Phylogenetic analysis of the HA genes revealed that $E M / W_{541}$ was evolutionarily close to the A/Yunnan/0127/2015-like H5N6 viruses isolated from poultry and environmental samples including fatal human cases in China during 2014-2016, and the HA genes belonged to the Group C of clade 2.3.4.4 HPAI H5 viruses (Figure 1).

The Group A and Group B of clade 2.3.4.4 viruses comprises $\mathrm{H}_{5} \mathrm{~N} 8$ viruses identified in South Korea in 2013/14 and 2014/15 winter seasons (November to February), respectively. Group C comprises $\mathrm{H}_{5} \mathrm{~N} 6$ viruses identified from China and Laos during 2013/14 and Group D comprises $\mathrm{H}_{5} \mathrm{~N} 6$ viruses identified from China and Vietnam during 2013/14. The NA gene was also derived from Group $\mathrm{C}_{5} \mathrm{H}_{5}$ 6-like viruses persisting in China during 2013-2014 (Figure 2) and the most closely related strain was A/GE/Hong Kong/00032/2016.

Although the other internal genes (PB2 (Figure 3), NP (Figure 4), M (Figure 5), and NS (Figure 6) can also be traced back to the Group $\mathrm{C} \mathrm{H}_{5}$ N6-like viruses(with the exception of PB1 and PA), they were clustered with different ancestors, such as A/SP/Guangdong/ ZH283/2015 and A/Dk/Guanzhou/41227/2014 (H5N6)like viruses. In contrast, the $\mathrm{PB} 1$ gene was closely related to $A / D k / G u a n g d o n g / S 4040 / 2011\left(H_{4} N 2\right)$ strains and the PA gene was closely related to $A / D k$ / Mongolia/20/2015 $\left(\mathrm{H}_{1} \mathrm{~N}_{1}\right)$ strains (Figures 7 and 8). The genotype map demonstrates that the first Korean $\mathrm{H}_{5} \mathrm{~N} 6$ viruses were reassorted from at least three different subtypes $\left(\mathrm{H}_{5} \mathrm{~N}_{6}, \mathrm{H}_{4} \mathrm{~N}_{2}\right.$ and $\left.\mathrm{H}_{1} \mathrm{~N}_{1}\right)$ present within the natural gene pool in Eurasian avian influenza viruses (Figure 9).

\section{Virulence in chickens}

To determine the pathogenicity of the EM/W541 in chickens, we initially measured the mean death times (MDT) and the intravenous pathogenicity index (IVPI) according to the recommendations outlined in the World Organisation for Animal Health (OIE) standards [19]. Briefly, 6.0 log10 egg infectious doses (EID50)/0.1 $\mathrm{mL}$ of the $\mathrm{H}_{5} \mathrm{~N} 6$ virus were intravenously inoculated into ten 6-week-old chickens which were then monitored until death. The MDT was 36 hours and the IVPI was 2.66 in chickens, suggesting the $E M / W_{541}$ virus should be classified as an HPAI virus according to OIE criteria [19].

\section{Conclusions}

Overall, we report the identification of a novel reassortant HPAI ${ }_{5} \mathrm{~N}_{6}$ virus that caused large outbreaks in 
domestic poultry in the late 2016 winter in South Korea [11]. This $\mathrm{H}_{5} \mathrm{~N} 6$ virus is a reassortant with multiple virus subtypes $\left(\mathrm{H}_{5} \mathrm{~N}_{6}, \mathrm{H}_{4} \mathrm{~N}_{2}\right.$ and $\left.\mathrm{H}_{1} \mathrm{~N}_{1}\right)$ from the gene pool in Eurasian avian influenza viruses. Initial animal studies revealed that this novel $\mathrm{H}_{5} \mathrm{~N} 6$ virus is highly pathogenic in chickens.

At this moment, it is hard to determine whether the presented reassortment event of the $\mathrm{H}_{5} \mathrm{~N} 6$ viruses occurred in 2016 during the wild bird migration into Korea or in a previous year and in another location before migration. Further detailed broad-range molecular studies are needed to elucidate when exactly the event occurred.

The first avian influenza $\mathrm{H}_{5} \mathrm{~N} 8$ (clade 2.3 .4 .4 ) virus outbreak was reported in poultry in South Korea in 2014. It rapidly spread worldwide, including to Europe and North America, by migratory wild birds [20]. This rapid and wide spread underscores the need for continuous, intensive surveillance of avian influenza viruses in wild migratory birds as it can be envisaged that these viruses may be transmitted for example to Europe, or possibly worldwide, by any migratory birds that use the same migratory flyways as the birds in the previous 2014 poultry outbreak in South Korea.

\section{${ }^{\star}$ Erratum}

The cells in the first row of the Table were erroneously shifted to the left. The table was corrected and replaced on 12 January 2017.

\section{Acknowledgements}

This work was supported by the Korea Health Technology R\&D Project through the Korea Health Industry Development Institute (KHIDI), funded by the Ministry of Health \& Welfare, Republic of Korea (Grant number: Hl16C1032). Animal experiments were progressed in an enhanced animal biosafety level 3 facility in Chungbuk National University permitted by the Korea-Centers for Disease Control and Prevention (K-CDC, permit number KCDC-14-3-07). All animal experiment protocols were approved by the Medical Research Institute and Laboratory Animal Research Center (LARC) (approval number CBNUA-1041-16-02).

\section{Conflict of interest}

None declared.

\section{Authors' contributions}

Wrote the manuscript: YK Choi, MS Song, EH Kim, YI Kim, HL Kwon, RJ Webby, and CJ Kim; performed laboratory investigations: YJ Si, IW Lee, EH Kim, SJ Park, HD Nguyen, SM Kim, JJ Kwon, WS Choi, YH Beak; performed phylogenetic analyses: YJ Si, YK Choi, HL Kwon, YI Kim; Animal experiment: EH Kim, HI Kwon, YI Kim, YJ Si, IW Lee. All authors reviewed the manuscript.

\section{References}

1. Patel S, Waugh J, Millar CD, Lambert DM. Conserved primers for DNA barcoding historical and modern samples from New Zealand and Antarctic birds.Mol Ecol Resour. 2010;10(3):431-8. DOI: 10.1111/j.1755-0998.2009.02793.x

2. Richard M, Herfst S, van den Brand JM, Lexmond P, Bestebroer TM, Rimmelzwaan GF, et al. Low virulence and lack of airborne transmission of the Dutch highly pathogenic avian influenza virus $\mathrm{H}_{5} \mathrm{~N} 8$ in ferrets. PLoS One. 2015;10(6):e0129827. DOI: 10.1371/journal.pone.0129827

3. Yang H, Carney PJ, Mishin VP, Guo Z, Chang JC, Wentworth DE, et al. Molecular Characterizations of Surface Proteins Hemagglutinin and Neuraminidase from Recent $\mathrm{H}_{5} \mathrm{Nx}$ Avian Influenza Viruses. J Virol. 2016;90(12):5770-84. DOI: 10.1128/ JVI.00180-16

4. Gu M, Liu W, Cao Y, Peng D, Wang X, Wan H, et al. Novel reassortant highly pathogenic avian influenza $\left(\mathrm{H}_{5} \mathrm{~N}_{5}\right)$ viruses in domestic ducks, China. Emerg Infect Dis. 2011;17(6):1060-3. DOI: 10.3201/eid/1706.101406

5. Kim Y-I, Pascua PNQ, Kwon H-I, Lim G-J, Kim E-H, Yoon S-W, et al. Pathobiological features of a novel, highly pathogenic avian influenza $\mathrm{A}\left(\mathrm{H}_{5} \mathrm{~N} 8\right)$ virus. Emerg Microbes Infect. 2014;3(10):e75. DOI: 10.1038/emi.2014.75

6. Bouwstra RI, Koch G, Heutink R, Harders F, van der Spek A, Elbers AR, et al. Phylogenetic analysis of highly pathogenic avian influenza $A\left(\mathrm{H}_{5} \mathrm{~N} 8\right)$ virus outbreak strains provides evidence for four separate introductions and one betweenpoultry farm transmission in the Netherlands, November 2014. Euro Surveill. 2015;20(26):21174. DOI: 10.2807/1560-7917. ES2015.20.26.21174

7. Ip HS, Torchetti MK, Crespo R, Kohrs P, DeBruyn P, Mansfield KG, et al. Novel Eurasian highly pathogenic avian influenza $A$ $\mathrm{H} 5$ viruses in wild birds, Washington, USA, 2014. Emerg Infect Dis. 2015;21(5):886-90. DOI: 10.3201/eid2105.142020

8. Wong FY, Phommachanh P, Kalpravidh W, Chanthavisouk C, Gilbert J, Bingham J, et al. Reassortant highly pathogenic influenza $A\left(\mathrm{H}_{5} \mathrm{N6}\right)$ virus in Laos. Emerg Infect Dis. 2015;21(3):511-6. DOI: 10.3201/eid2103.141488

9. Sun H, Pu J, Wei Y, Sun Y, Hu J, Liu L, et al. Highly pathogenic avian influenza $\mathrm{H}_{5} \mathrm{~N} 6$ viruses exhibit enhanced affinity for human type sialic acid receptor and in-contact transmission in model ferrets. J Virol. 2016;90(14):6235-43. DOI: 10.1128 JVI.00127-16

10. World Health Organization (WHO). Influenza at the human animal interface. Geneva: WHO; 2016. [Accessed 18 Nov 2016] Available from: http://www.who.int/influenza/human_animal. interface/Influenza_Summary_IRA_HA_interface_11_15_2016. pdf

11. World Organisation for Animal Health (OIE). Update on highly pathogenic avian influenza in animals (TYPE $\mathrm{H}_{5}$ and H7). Paris: OlE; 2016. [Accessed 29 Dec 2016]. Available from: http://www.oie.int/animal-health-in-the-world/ update-on-avian-influenza/2016/

12. Mok CKP, Da Guan W, Liu XQ, Lamers MM, Li XB, Wang M, et al. Genetic characterization of highly pathogenic avian influenza A ( $\left.\mathrm{H}_{5} \mathrm{~N} 6\right)$ virus, Guangdong, China. Emerg Infect Dis. 2015;21(12):2268-71. DOI: 10.3201/eid2112.150809

13. He J, Duan J. First human case of avian influenza $A\left(\mathrm{H}_{5} \mathrm{~N} 6\right)$ in Yunnan province, China. SAGE Open Med Case Rep. 2015 Aug 4. doi: DOI: $10.1177 / 2050313 X_{15596484}$. eCollection 2015.DOI: 10.1177/2050313X15596484

14. Watanabe Y, Ibrahim MS, Ellakany HF, Kawashita N, Mizuike $\mathrm{R}$, Hiramatsu $\mathrm{H}$, et al. Acquisition of human-type receptor binding specificity by new $\mathrm{H}_{5} \mathrm{~N}_{1}$ influenza virus sublineages during their emergence in birds in Egypt. PLoS Pathog. 2011;7(5):e1002068. DOI: 10.1371/journal.ppat.1002068

15. Zhu X, Viswanathan K, Raman R, Yu W, Sasisekharan R, Wilson IA. Structural Basis for a Switch in Receptor Binding Specificity of Two $\mathrm{H}_{5} \mathrm{~N}_{1}$ Hemagglutinin Mutants.Cell Reports. 2015;13(8):1683-91. DOI: 10.1016/j.celrep.2015.10.027

16. Zamarin D, Ortigoza MB, Palese P. Influenza A virus PB1-F2 protein contributes to viral pathogenesis in mice.J Virol. 2006;80(16):7976-83. DOI: 10.1128/JVI.00415-06

17. Das K, Ma L-C, Xiao R, Radvansky B, Aramini J, Zhao L, et al. Structural basis for suppression of a host antiviral response by influenza A virus. Proc Natl Acad Sci USA. 2008;105(35):130938. DOI: $10.1073 /$ pnas.0805213105

18. Soubies SM, Volmer C, Croville G, Loupias J, Peralta B, Costes $P$, et al. Species-specific contribution of the four C-terminal amino acids of influenza A virus NS1 protein to virulence. J Virol. 2010;84(13):6733-47. DOI: 10.1128/JVI.02427-09

19. World Organisation for Animal Health (OIE). OIE Terrestrial Manual 2015. Chapter 2.3.4 Avian influenza (Infection with avian influenza viruses). Paris: OIE; 2015. [Accessed 8 Jun 
2016]. Available from http://www.oie.int/fileadmin/Home/eng/ Health_standards/tahm/2.03.04_Al.pdf

20. Lycett SJ, Bodewes R, Pohlmann A, Banks J, Bányai K, Boni MF, et al. Global Consortium for $\mathrm{H}_{5} \mathrm{~N} 8$ and Related Influenza Viruses. Role for migratory wild birds in the global spread of avian influenza H5N8. Science. 2016;354(6309):213-7. DOI: $10.1126 /$ science.aaf 8852

\section{License and copyright}

This is an open-access article distributed under the terms of the Creative Commons Attribution (CC BY 4.0) Licence. You may share and adapt the material, but must give appropriate credit to the source, provide a link to the licence, and indicate if changes were made.

This article is copyright of the authors, 2017. 